\title{
Molecular Identification of Spirometra erinaceieuropaei Tapeworm in Cases of Human Sparganosis, Hong Kong
}

\author{
Tommy H.C. Tang, ${ }^{1}$ Samson S.Y. Wong, ${ }^{1}$ \\ Christopher K.C. Lai, ${ }^{2}$ Rosana W.S. Poon, ${ }^{2}$ \\ Helen S.Y. Chan, Tak Chiu Wu, \\ Yuk-Fai Cheung, Tak-Lap Poon, Yi-Po Tsang, \\ Wai-Lun Tang, Alan K.L. Wu
}

Human sparganosis is a foodborne zoonosis endemic in Asia. We report a series of 9 histologically confirmed human sparganosis cases in Hong Kong, China. All parasites were retrospectively identified as Spirometra erinaceieuropaei. Skin and soft tissue swelling was the most common symptom, followed by central nervous system lesions.

Q parganosis is a parasitic zoonosis endemic in Asia, Europe, and North America. Diphyllobothroid tapeworm under the genus Spirometra is the causative agent. Humans can be infected through the consumption of contaminated water or meat from intermediate hosts or through topical application of raw, contaminated poultices to eyes and open wounds. After entry into humans, the plerocercoid larvae (spargana) migrate to different anatomic locations, where they cause space-occupying lesions as they develop into adults. The sites spargana migrate to include skin and soft tissues, muscles, visceral organs, and the central nervous system. Clinical symptoms range from asymptomatic/mild (e.g., subcutaneous swelling) to severe (e.g., seizure and hemiparesis) depending on the site and size of lesions (1).

Sparganosis is an emerging zoonotic disease and public health challenge in China, potentially because of the practice of consuming wild frog meat, which is a delicacy in the southern Guangdong province. According to a 2009 survey, $>25 \%$ of the local wild frogs were infected with spargana (2). Most cases of human sparganosis have been found in Asia, with the highest cumulative number in China (online Technical Appendix Table, https://wwwnc. cdc.gov/EID/article/23/4/16-0791-Techapp1.pdf) (3). In Hong Kong, the earliest known cases of sparganosis were 2 subcutaneous infections reported in 1962 (4), and cases

Author affiliations: Queen Elizabeth Hospital, Hong Kong, China

(T.H.C. Tang, C.K.C. Lai, H.S.Y. Chan, T.C. Wu, Y.-F. Cheung,

T.-L. Poon); The University of Hong Kong, Hong Kong

(S.S.Y. Wong, R.W.S. Poon); Pamela Youde Nethersole Eastern

Hospital, Hong Kong (Y.-P. Tsang, W.-L. Tang, A.K.L. Wu)

DOI: http://dx.doi.org/10.3201/eid2304.160791 afterward have been sporadic. With advances in molecular sequencing, the identification of sparganum larvae isolated from humans was made possible $(5,6)$. In this study, we performed molecular sequencing on archived histologic specimens to delineate the parasites down to species level.

\section{The Study}

Cases of human sparganosis were identified by searching the clinical, parasitologic, and histopathologic records in the Queen Elizabeth Hospital and the Pamela Youde Nethersole Eastern Hospital in Hong Kong. Archived histopathology specimens showing parasites compatible with plerocercoids were retrieved for further molecular testing. We made 10-15 (depending on the amount of tissue available) 4- $\mu \mathrm{m}$ sections from each paraffin block; the sections were deparaffinized and suspended in sterile, normal saline. Genomic DNA was extracted from formalin-fixed paraffin-embedded tissue by using a DNA minikit (QIAGEN, Hilden, Germany) according to the manufacturer's instructions. The DNA was eluted in $60 \mu \mathrm{L}$ of elution buffer and used as template for PCR.

Primer sequences used in this study were cox1-F 5'-CGGCTTTTTTTGATCCTTTGGGTGG-3', cox1R 5'-GTATCATATGAACAACCTAATTTAC-3', 28S-F 5'-CACCGAAGC CTGCGGTA-3', and 28S-R 5'-GAAGGTCGACCTGGTGAA-3', which targeted specifically to the cox 1 and 28S rRNA genes of $S$. erinaceieuropaei respectively (7). The later primers were designed inhouse by multiple alignments of different parasite species. The PCR mixture $(25 \mu \mathrm{L})$ contained DNA, PCR buffer $(10$ $\mathrm{mmol} / \mathrm{L}$ Tris- $\mathrm{HCl}[\mathrm{pH} 8.3], 50 \mathrm{mmol} / \mathrm{L} \mathrm{KCl}, 3 \mathrm{mmol} / \mathrm{L}$ $\mathrm{MgCl}_{2}$, and $0.01 \%$ gelatin), and $200 \mathrm{mmol} / \mathrm{L}$ each deoxynucleoside triphosphate (dNTP) and 1.0 U Taq polymerase (Applied Biosystems, Foster City, CA, USA). The mixtures were amplified in 60 cycles of $94^{\circ} \mathrm{C}$ for $1 \mathrm{~min}, 55^{\circ} \mathrm{C}$ for $1 \mathrm{~min}$, and $72^{\circ} \mathrm{C}$ for $1 \mathrm{~min}$ with a final extension at $72^{\circ} \mathrm{C}$ for $10 \mathrm{~min}$ in an automated thermal cycler (Applied Biosystems). Standard precautions were taken to avoid PCR contamination, and no false-positive results were observed in negative controls. PCR products were gel purified by using the QIAquick gel extraction kit (QIAGEN). Both strands of the PCR products were sequenced twice with an ABI Prism

${ }^{1}$ These first authors contributed equally to this article.

${ }^{2}$ These authors contributed equally to this article. 
3700 DNA analyzer (Applied Biosystems). Sequences of the PCR products were compared with known sequences by BLAST analysis (https://blast.ncbi.nlm.nih.gov).

We constructed a phylogenetic tree using the neighborjoining method with Kimura's 2-parameter correction with ClustalX 1.83 (http://www.clustal.org). We included in the analysis the $252 \mathrm{bps}$ and $211 \mathrm{bps}$ of the amplicon from the coxl gene (GenBank accession nos. KU760072-81) and the 28S rRNA gene (accession nos. KX831668-77) of $S$. erinaceieuropaei, respectively, detected in positive samples. Strongyloides stercoralis was used as the outgroup in these analyses.

Seven patients with human sparganosis were identified in Queen Elizabeth Hospital, and 2 patients were identified in the Pamela Youde Nethersole Eastern Hospital. All diagnoses were made from 1999 to 2015 (Table). Eight patients were Chinese; 1 was Filipino, and 4 were male. Patient age at diagnosis was 29-73 (median 49) years. Three patients displayed neurologic symptoms, such as numbness, weakness, or memory impairment, and the other 6 displayed skin and soft tissue involvement. All had progressively enlarging or migratory skin nodules (Table). Additional information on clinical history, histopathology, and magnetic resonance brain imaging of representative cases was collected (online Technical Appendix).
Nine patients had archived histopathologic specimens available for molecular testing. Parasite identification was achieved in all 9 specimens, and they showed $99 \%-100 \%$ and $100 \%$ identity with the cox 1 and $28 \mathrm{~S}$ rRNA gene sequences of S. erinaceieuropaei, respectively (Figure, panels A and B).

\section{Conclusions}

This study demonstrates that human sparganosis appeared sporadically in Hong Kong. The most common signs of disease were skin and soft tissue nodules followed by intracranial lesions. By molecular sequencing, the tested parasites were $S$. erinaceieuropaei. We were unable to pinpoint the source of infection in most patients; the incubation period can last as long as several months, and early stages of the disease are usually asymptomatic (8). Patients might have difficulty recalling specific high-risk exposures. In most industrialized countries, the practice of applying raw frog or snake poultices to open wounds is regarded as unhygienic and becoming obsolete, yet consumption of undercooked frog meat or, less commonly, ingestion of raw snake bile for medicinal purposes is still practiced in Hong Kong. Another possible route of transmission could have been drinking water contaminated with Spirometra procercoids.

Subcutaneous sparganosis is the most commonly recognized form of the disease. Because sparganosis is rare, it

Table. Characteristics of cases of human sparganosis, Hong Kong, 1999-2015

\begin{tabular}{|c|c|c|c|c|c|c|c|c|}
\hline $\begin{array}{l}\mathrm{Pt} \\
\text { no. }\end{array}$ & Year & $\begin{array}{l}\text { Age, } \\
\text { y/sex }\end{array}$ & Ethnicity & $\begin{array}{c}\text { Probable } \\
\text { place/mode of } \\
\text { infection }\end{array}$ & $\begin{array}{c}\text { Location of } \\
\text { lesion }\end{array}$ & $\begin{array}{l}\text { Size of worm or } \\
\text { lesion, } \mathrm{cm}\end{array}$ & Clinical features & $\begin{array}{c}\text { PEC, } \times 10^{9} / L \\
\text { (\% total WBC } \\
\text { count) }\end{array}$ \\
\hline 1 & 1999 & $67 / F$ & Chinese & Unk/Unk & Right breast & $\begin{array}{c}0.15 \times 0.1 \times 0.7 \\
0.15 \times 0.1 \times 0.7 \\
0.1 \times 0.5 \times 0.5 \\
\text { (lesions excised) }\end{array}$ & Right breast mass & NR \\
\hline 2 & 2000 & $46 / \mathrm{M}$ & Chinese & Unk/Unk & NR & 0.15 (worm length) & NR & NR \\
\hline 3 & 2002 & $29 / F$ & Chinese & Unk/Unk & $\begin{array}{l}\text { Epigastrium of } \\
\text { abdominal } \\
\text { wall }\end{array}$ & $\begin{array}{c}4 \times 2.5 \times 2 \text { (lesion } \\
\text { excised) }\end{array}$ & NR & NR \\
\hline$\overline{4}$ & 2003 & $63 / F$ & Chinese & Unk/Unk & Left thigh & $\begin{array}{c}0.6 \text { (maximum } \\
\text { dimension of lesion } \\
\text { excised) }\end{array}$ & $\begin{array}{l}\text { Progressive enlarging mass } \\
\text { for } 2 \text { years }\end{array}$ & NR \\
\hline 5 & 2004 & $44 / \mathrm{M}$ & Chinese & Unk/Unk & Right thigh & $\begin{array}{l}1.5 \times 1.5 \text { (lesion) } \\
0.27 \times 0.2 \times 0.5\end{array}$ & $\begin{array}{l}\text { Right thigh nodule for } 6 \\
\text { months }\end{array}$ & NR \\
\hline
\end{tabular}

$2014-55 / M \quad$ (worm)

$2014 \quad$ 55/M Unk/Unk Right thigh

$1.6 \times 1.3 \times 1.4 \quad$ Recurrent right thigh nodule;

$0.22(3.7)$ and suspected (lesion) suspicious $2 \times 5 \times 5 \mathrm{~mm}$ T2W/FLAIR hyperintensity with contrast enhancement in left frontal white matter

\begin{tabular}{|c|c|c|c|c|c|c|c|c|}
\hline 6 & 2005 & $43 / F$ & Chinese & Unk/Unk & Left breast & $\begin{array}{l}0.21 \text { (lesion } \\
\text { excised) }\end{array}$ & $\begin{array}{c}\text { Progressive enlarging left } \\
\text { breast mass }\end{array}$ & $0.1(0.7)$ \\
\hline 7 & 2011 & $58 / \mathrm{M}$ & Chinese & $\begin{array}{l}\text { China/ingestion } \\
\text { of frogs and } \\
\text { snakes }\end{array}$ & Left chest wall & $3 \times 2.5 \times 1$ (lesion) & $\begin{array}{c}\text { Left chest wall mass for } 3 \\
\text { years }\end{array}$ & $0.21(2.5)$ \\
\hline 8 & 2013 & $49 / F$ & Filipino & Unk/Unk & $\begin{array}{l}\text { Left parietal } \\
\text { lobe }\end{array}$ & $\begin{array}{c}0.17 \times 0.12 \times 0.23 \\
\text { (lesion) }\end{array}$ & $\begin{array}{l}\text { Right-sided numbness and } \\
\text { weakness for } 2 \text { days }\end{array}$ & $0.1(1.1)$ \\
\hline 9 & 2015 & 73/M & Chinese & $\begin{array}{l}\text { China/ingestion } \\
\text { of frogs }\end{array}$ & Left thigh & $\begin{array}{c}0.5 \times 0.5 \times 0.1 \\
\text { (lesion excised) }\end{array}$ & $\begin{array}{l}\text { Progressive enlarging left } \\
\text { inner thigh mass for } 1 \text { year }\end{array}$ & $0.21(4.2)$ \\
\hline
\end{tabular}


is seldom considered during an initial patient assessment, although a migratory nodule might raise the suspicion for a helminthic etiology. Diagnosis of sparganosis needs to be confirmed, normally by studying the excised lesions. Even though serologic tests for sparganosis have been described, these assays are not generally available and their performance requires more evaluation (9-13). In contrast, the presence of tunnel sign, conglomerated rings, beadshaped enhancements, or images of parasites of various life stages by computerized tomography or magnetic resonance

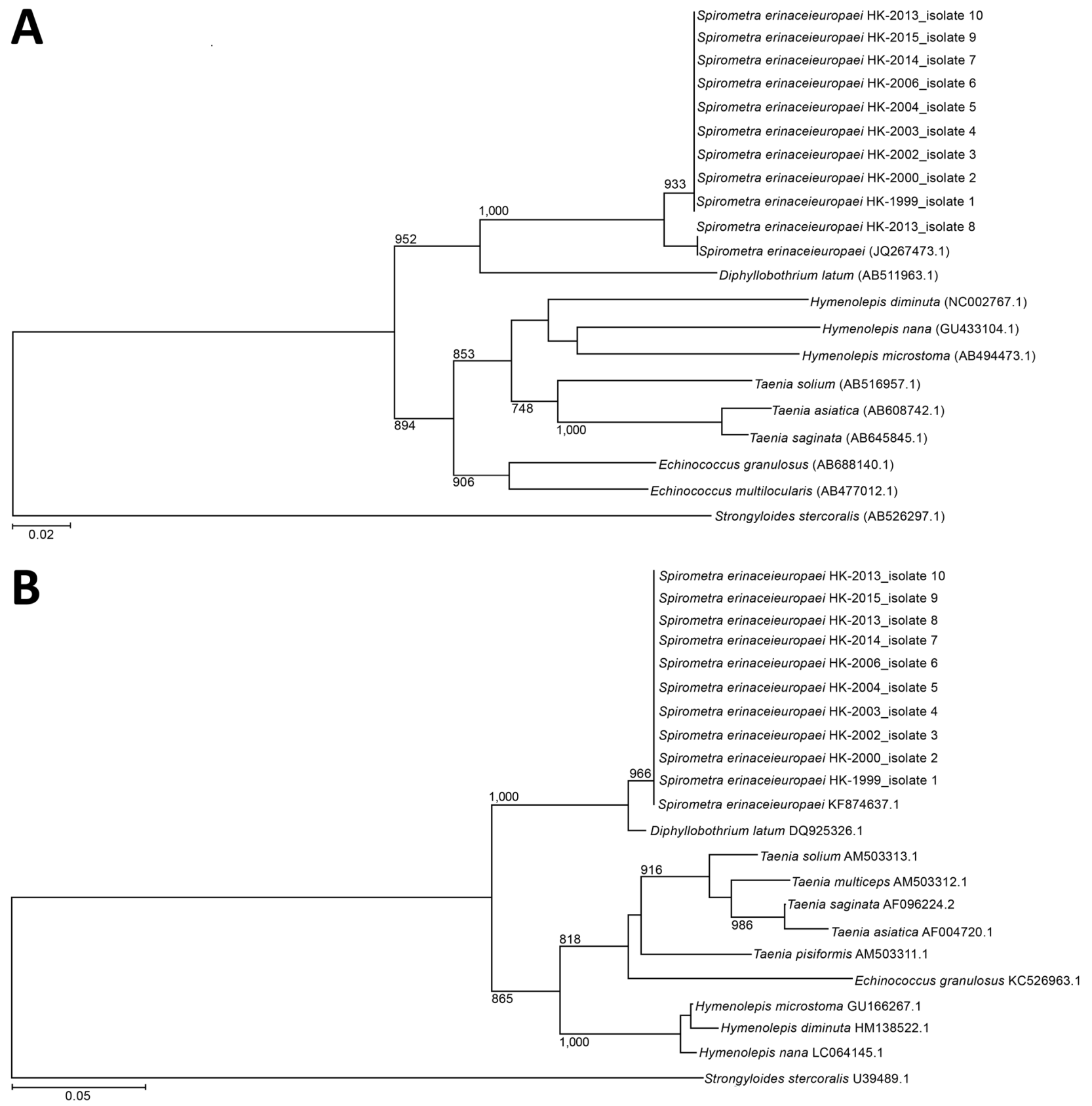

Figure. Phylogenetic analysis of cox1 and 28S rRNA genes of archived formalin-fixed paraffin-embedded tissues obtained from human sparganosis cases, Hong Kong, 1999-2015. A) A 252-bp sequence from the cox1 gene (GenBank accession nos. KU760072-81) was included for each isolate. B) A 211-bp sequence from the 28S rRNA gene (accession nos. KX831668-77) was included for each isolate. Trees were constructed by using the neighbor-joining method and rooted with the corresponding sequence in Strongyloides stercoralis (accession nos. AB526297.1 and U39489.1 for cox1 and 28S rRNA genes, respectively). The bootstrap values are shown for nodes that appeared in $>70 \%$ of the 1,000 replicates. The species used for comparison and their GenBank accession numbers are given in the tree. Scale bars indicate estimated number of substitutions per 50 bases. 
imaging are suggestive of sparganosis (14). Histopathologic diagnosis of parasitic infections remains a challenge to pathologists in countries where sparganosis is not endemic. Recognizing the different phyla and classes of parasites (i.e., nematodes, cestodes, and trematodes) histologically is usually simple. However, specific identification of the genus and species requires substantial expertise in parasite pathology and morphology. Identification of rare parasites is sometimes impossible because of the lack of detailed morphologic descriptions in the literature. Under such circumstances, molecular studies provide useful information for species identification (15). Nevertheless, it is not infallible, especially for rare parasites, because precise species identification depends on gene sequence availability and data accuracy.

Although the parasitic drug praziquantel has wide coverage against several cestodes and trematodes, its efficacy in the treatment of sparganosis remains uncertain. Surgical intervention for complete worm removal should be used whenever feasible.

This study had limitations. We only included information on patients from 2 of the 7 geographic clusters of public hospitals in Hong Kong, and those with asymptomatic subcutaneous lesions most likely did not seek medical attention. The reported number is certainly an underestimate.

Given that human sparganosis is an emerging zoonotic parasitic infection, clinicians may consider it in the differential diagnosis for mass lesions with undetermined etiology. Education of the general public about food safety, including avoiding the consumption of untreated water and undercooked frog and snake meat, is needed.

\section{Acknowledgments}

We thank Sherman Lo for providing magnetic resonance imaging brain scans.

Dr. Tang is the associate consultant of the Division of Infectious Diseases in the Department of Medicine at Queen Elizabeth Hospital. His research interests are emerging infectious diseases, infections in immunocompromised hosts, infectious disease epidemiology, and global health.

\section{References}

1. Liu Q, Li MW, Wang ZD, Zhao GH, Zhu XQ. Human sparganosis, a neglected food borne zoonosis. Lancet Infect Dis. 2015;15:122635. http://dx.doi.org/10.1016/S1473-3099(15)00133-4

2. Li MW, Lin HY, Xie WT, Gao MJ, Huang ZW, Wu JP, et al. Enzootic sparganosis in Guangdong, People's Republic of China. Emerg Infect Dis. 2009;15:1317-8. http://dx.doi.org/10.3201/ eid1508.090099
3. Zhang X, Cui J, Liu LN, Jiang P, Wang H, Qi X, et al. Genetic structure analysis of Spirometra erinaceieuropaei isolates from central and southern China. PLoS One. 2015;10:e0119295. http://dx.doi.org/10.1371/journal.pone.0119295

4. Huang CT, Kirk R. Human sparganosis in Hong Kong. J Trop Med Hyg. 1962;65:133-8.

5. Boonyasiri A, Cheunsuchon P, Suputtamongkol Y, Yamasaki H, Sanpool O, Maleewong W, et al. Nine human sparganosis cases in Thailand with molecular identification of causative parasite species. Am J Trop Med Hyg. 2014;91:389-93. http://dx.doi.org/10.4269/ ajtmh.14-0178

6. Jeon HK, Park H, Lee D, Choe S, Kim KH, Huh S, et al. Human Infections with Spirometra decipiens plerocercoids identified by morphologic and genetic analyses in Korea. Korean J Parasitol. 2015;53:299-305. http://dx.doi.org/10.3347/ kjp.2015.53.3.299

7. Koonmee S, Intapan PM, Yamasaki H, Sugiyama H, Muto M, Kuramochi T, et al. Molecular identification of a causative parasite species using formalin-fixed paraffin embedded (FFPE) tissues of a complicated human pulmonary sparganosis case without decisive clinical diagnosis. Parasitol Int. 2011;60:460-4. http://dx.doi.org/10.1016/j.parint.2011.07.018

8. Tappe D, Berger L, Haeupler A, Muntau B, Racz P, Harder Y, et al. Case report: molecular diagnosis of subcutaneous Spirometra erinaceieuropaei sparganosis in a Japanese immigrant. Am J Trop Med Hyg. 2013;88:198-202. http://dx.doi.org/10.4269/ ajtmh.2012.12-0406

9. Yeo IS, Yong TS, Im K. Serodiagnosis of human sparganosis by a monoclonal antibody-based competition ELISA. Yonsei Med J. 1994;35:43-8. http://dx.doi.org/10.3349/ymj.1994.35.1.43

10. Cui J, Li N, Wang ZQ, Jiang P, Lin XM. Serodiagnosis of experimental Sparganum infections of mice and human sparganosis by ELISA using ES antigens of Spirometra mansoni spargana. Parasitol Res. 2011;108:1551-6. http://dx.doi.org/ 10.1007/s00436-010-2206-2

11. Rahman SMM, Kim JH, Hong ST, Choi MH. Diagnostic efficacy of a recombinant cysteine protease of Spirometra erinacei larvae for serodiagnosis of sparganosis. Korean J Parasitol. 2014;52:41-6. http://dx.doi.org/10.3347/kjp.2014.52.1.41

12. Liu LN, Zhang X, Jiang P, Liu RD, Zhou J, He RZ, et al. Serodiagnosis of sparganosis by ELISA using recombinant cysteine protease of Spirometra erinaceieuropaei spargana. Parasitol Res. 2015;114:753-7. http://dx.doi.org/10.1007/ s00436-014-4270-5

13. Liu LN, Wang ZQ, Zhang X, Jiang P, Qi X, Liu RD, et al. Characterization of Spirometra erinaceieuropaei plerocercoid cysteine protease and potential application for serodiagnosis of sparganosis. PLoS Negl Trop Dis. 2015;9:e0003807. http://dx.doi.org/10.1371/journal.pntd.0003807

14. Lo Presti A, Aguirre DT, De Andrés P, Daoud L, Fortes J, Muñiz J. Cerebral sparganosis: case report and review of the European cases. Acta Neurochir (Wien). 2015;157:1339-43, discussion 1343. http://dx.doi.org/10.1007/s00701-015-2466-9

15. Wong SSY, Fung KSC, Chau S, Poon RWS, Wong SCY, Yuen KY. Molecular diagnosis in clinical parasitology: when and why? Exp Biol Med (Maywood). 2014;239:1443-60. http://dx.doi.org/10.1177/1535370214523880

Address for correspondence: Tommy H.C. Tang, Division of Infectious

Diseases, Department of Medicine, Queen Elizabeth Hospital, 30

Gascoigne Rd, Hong Kong, China; email: thc061@gmail.com 